\title{
ENTRE TIPOS E RADICAIS: A CONSTRUÇ̃̃O DO CONCEITO DE VALÊNCIA
}

Helena S. Alvares Nogueira ${ }^{\mathrm{a}, *}$ e Paulo Alves Porto ${ }^{\mathrm{b},}, \odot$

a'Instituto de Química, Universidade de São Paulo, 05508-000 São Paulo - SP, Brasil

bDepartamento de Química Fundamental, Instituto de Química, Universidade de São Paulo, 05508-000 São Paulo - SP, Brasil

Recebido em 03/09/2018; aceito em 22/10/2018; publicado na web em 28/11/2018

\begin{abstract}
BETWEEN TYPES AND RADICALS: THE CONSTRUCTION OF THE CONCEPT OF VALENCE. This paper presents a historical case study regarding the development of the concept of valence in late nineteenth and early twentieth centuries. The case study focuses on Edward Frankland's contribution to the process which lead to the convergence of two theories about the combination of the elements: the theory of types and the theory of radicals. Results show how such process involved many other scientists from various countries and how the concept of valence related to studies on bonding, periodicity and chemical structure. Changes in the nomenclature and notation were also observed. In the beginning of the twentieth century, the empirical concept of valence received theoretical explanations under the light of the then new theories on electronic structure of atoms. Thus, this case study exemplifies the complexity of the process of development of a scientific concept and, in particular, shows the multiplicity of connections of the concept of valence in the body of chemical knowledge.
\end{abstract}

Keywords: valence; history of chemistry; theory of types; theory of radicals; chemical bonding; Edward Frankland.

\section{INTRODUÇÃO}

O conceito de valência, assim como outros conceitos científicos, foi sendo construído e reconstruído ao longo dos anos, até se tornar o que conhecemos hoje. Entre o final do século XIX e o início do século $\mathrm{XX}$, o conceito ganhou destaque nos trabalhos de diversos químicos, tanto orgânicos quanto inorgânicos, e no século XX se modificou com as novas teorias atômicas e contribuições originadas na física quântica. ${ }^{1-4}$

O presente trabalho tem como objetivo investigar a contribuição de Edward Frankland (1825 - 1899) na construção do conceito de valência, partindo da hipótese de que esse personagem desempenhou um importante papel de sumarizar concepções semelhantes, propostas por autores contemporâneos, em um processo que conduziu, simultaneamente, à amalgamação da teoria dos tipos com a teoria dos radicais. Assim, focalizamos a questão acerca de como as ideias de Frankland, relacionadas às concepções de Friedrich August Kekulé (1829 - 1896) para os compostos de carbono, convergiram no conceito de valência. Adicionalmente, levando em conta que a mudança da noção clássica de valência para uma concepção quântica para os átomos poderia ser considerada como uma ruptura paradigmática (considerando o entendimento kuhniano de paradigma), poder-se-ia perguntar como foi encaminhada essa transição. Dessa forma, pretende-se contribuir para a compreensão da origem e das transformações do conceito de valência, que ainda hoje é relevante, especialmente no contexto do ensino superior e médio de química. ${ }^{5-13}$

Nossa abordagem segue parâmetros da contemporânea historiografia da ciência, buscando compreender a construção do conceito de valência no contexto em que foi proposto, conforme as teorias e metodologias do período. Para isso, recorremos a fontes primárias (publicações de cientistas da época em análise) e secundárias (produções de historiadores da ciência que se dedicaram ao tema, revisitados de maneira crítica) ${ }^{14-16}$ Conforme aponta Canguilhem, o objeto da história da ciência é dinâmico: à medida que a própria ciência se transforma com o passar do tempo, os discursos produzidos sobre ela são ressignificados - de modo que a historiografia da ciência periodicamente se renova. ${ }^{17}$

*e-mail: helena.savignani.leite@usp.br
Dessa forma, o estudo de caso histórico aqui apresentado foi guiado pela investigação das diferentes teorias que influenciaram e foram influenciadas pela teoria de valência, considerando seus principais formuladores, os locais em que essas teorias foram criadas e desenvolvidas, e os problemas que visavam responder, delineando o contexto de sua formulação.

\section{A CONSTRUÇÃo DO CONCEITO DE VALÊNCIA}

Na atualidade, o conceito de valência ainda está presente nas aulas e nos livros de química geral, sendo útil para a formação e no trabalho dos químicos. Segundo o Compendium of Chemical Terminology (também conhecido como Gold Book) da IUPAC, valência (em inglês, valence) se refere ao número máximo de átomos univalentes, como o hidrogênio, a que o átomo sob consideração pode se unir ou substituir. Para além dessa definição clássica, o termo "valência" é encontrado adjetivando vários outros termos, como nas expressões camada de valência, elétrons de valência, ligação de valência e outras. Ou seja, embora a definição clássica não tenha sido totalmente superada, o termo tem abrangência mais ampla e é utilizado em várias áreas da química, o que pode ser observado desde o final do século XIX e início do século XX, com o advento da teoria estrutural e da quântica.

Kuznetsov procurou caracterizar as mudanças no nome atribuído ao conceito que hoje chamamos de valência. ${ }^{18}$ Outros termos foram usados previamente, tais como: basicidade, proposto em 1852 por Alexander Williamson (1824 - 1904); atomicidade, usado em 1857 por Kekulé; equivalência e quantivalência, usados também por Kekulé a partir de 1858. Nesse momento, surgiria nos trabalhos de Kekulé o termo valência, como uma forma reduzida e abreviada das palavras "equivalência" e "quantivalência". Esses três termos estariam relacionados pela mesma raiz latina, valens (de valere, que entre outras acepções tem o sentido de "estar forte"), cujo significado estaria ligado à ideia de força. Assim, a palavra "valência" sugeria um "poder" ou uma "força de combinação" existente entre dois elementos. ${ }^{18}$

A transformação do conceito ao longo do tempo esteve relacionada, além das conexões teóricas, com o aperfeiçoamento de técnicas e equipamentos de análise durante o século XIX, realizado por químicos visando à produção e caracterização de novos materiais e 
substâncias, principalmente orgânicas. ${ }^{19,20}$ Isso pode ser constatado em artigos de Frankland, nos quais o autor destaca a importância de modificações promovidas em certos instrumentos e técnicas, tais como: o aperfeiçoamento de eudiômetros (aparelhos para análise de gases); o desenvolvimento de equipamentos para destilação e coleta de substâncias sensíveis a reações com oxigênio ou com a umidade do ar; e de reatores para resistir a elevadas pressões decorrentes da formação de gases. ${ }^{21-23}$

Desde meados do século XIX, já se considerava a importância do conceito de valência para os estudos sobre a estrutura da matéria. ${ }^{24}$ Então chamado de atomicidade, o conceito ganhou força nos trabalhos de Kekulé, Alexander Butlerov (1828 - 1886), Frankland, Archibald Couper (1831 - 1892), Alfred Werner (1866 - 1919), entre outros, durante o período compreendido entre o final do século XIX e o início do século XX. ${ }^{2-4,24} \mathrm{~A}$ história registra uma clássica disputa entre Kekulé e Werner, que respectivamente defendiam ser constante ou variável a natureza da valência de um elemento. ${ }^{18,25,26}$ Já no século $\mathrm{XX}$, o conceito de valência sofreu as influências de novas teorias atômicas, como nos trabalhos de Gilbert Lewis (1875 - 1946), ${ }^{27,28}$ e, posteriormente, da mecânica quântica. Essa evolução foi dividida em três períodos por Araújo Neto, caracterizados pela emergência e desenvolvimento do conceito, entre os anos de 1850 e 1870; pela ampla divulgação e utilização do conceito, entre os anos de 1870 e 1920; e por fim, após 1920, pela modificação do conceito pela aplicação e influência da mecânica quântica. ${ }^{4}$

Ao longo da trajetória de construção e modificação do conceito de valência, é possível observar sua transformação de um conceito que visava explicar a estrutura química de compostos orgânicos para um conceito que atualmente é usado para descrever as ligações químicas, tanto em moléculas orgânicas quanto inorgânicas.

Dessa forma, o conceito de valência e sua construção ao longo dos séculos XIX e XX é um exemplo de como a ciência evolui por cooperação e interdependência. A história do conceito de valência mostra vários cientistas que trabalharam em teorias distintas (teoria dos radicais e teoria dos tipos) e por toda a Europa, principalmente Alemanha (onde havia uma forte química orgânica sintética e estudos sobre afinidade química), Inglaterra (estudos sobre eletroquímica e sobre modelos atômicos) e França (país consagrado como berço da "nova química" de Antoine Lavoisier [1743 - 1794] e seus colaboradores, e no qual também se destacaram os estudos sobre afinidade química). Não se pode desconsiderar que a forte presença da química em vários países da Europa se deve também ao estabelecimento de instituições de ensino de ciências, de sociedades científicas e ao intercâmbio entre seus membros nos séculos XVIII e XIX. ${ }^{29-32}$ Embora muitas discussões e disputas de autoridade ou por apoio tenham ocorrido, essa diversidade de pesquisas e pessoas levou a uma evolução relativamente rápida do conceito de valência e à resolução de problemas da época, como o estabelecimento de fórmulas estruturais e a caracterização dos produtos de reações químicas. ${ }^{25}$

A transformação das ideias sobre valência somente foi possível devido a outros conceitos que já estavam, de certa forma, estabelecidos, e que geraram um contexto científico favorável. Esse contexto incluía, no caso em estudo: a invenção da pilha e o desenvolvimento da eletroquímica; a teoria atômica de Dalton; a lei da composição constante e a lei das proporções múltiplas; o dualismo de Lavoisier e Jöns Jacob Berzelius (1779 - 1848); e o amplo trabalho de síntese e caracterização de compostos orgânicos. ${ }^{30}$ Esses conceitos não eram consensualmente aceitos pela comunidade científica da época - principalmente a teoria atômica, pois havia ainda uma grande desconfiança sobre a real existência dos átomos como entidades físicas indivisíveis. Entre os nomes envolvidos na construção da teoria de valência, havia apoiadores e opositores da concepção de átomos. Williamson, por exemplo, utilizou a teoria da valência para defender a teoria atômica, enquanto Frankland a utilizou para demonstrar que uma teoria metafísica - como era considerada por muitos a teoria atômica, por não possuir evidências diretas - não era necessária para explicar os compostos químicos. ${ }^{33,34}$ Por fim, é preciso considerar a importância do estudo da química orgânica para o desenvolvimento econômico, principalmente da Alemanha, uma vez que o crescimento e aprimoramento das sínteses orgânicas permitiram a significativa expansão das indústrias químicas, que se tornaram uma grande força econômica na Europa. ${ }^{35}$

O presente estudo de caso mostra diferentes facetas do desenvolvimento do conceito de valência. Inicialmente, são focalizados alguns dos cientistas - em especial, Frankland - cujos trabalhos estão relacionados à construção desse conceito, bem como as mudanças na nomenclatura e notação da valência. Após essa parte introdutória, são focalizadas as duas rotas principais que foram concorrentes durante um período, e que depois deram origem à teoria de valência: a teoria dos tipos e a teoria dos radicais. ${ }^{30}$ Embora aqui sejam diferenciadas, as duas teorias se confundiam muitas vezes, e os autores da época podiam migrar de uma para outra com certa facilidade. ${ }^{36}$ Finalmente, se aborda a aplicação do conceito de valência nos estudos sobre estrutura, ligação e periodicidade química, no contexto da transição dos modelos clássicos para a abordagem quântica da estrutura atômica.

\section{ALGUNS CIENTISTAS ENVOLVIDOS}

Muitos cientistas estiveram envolvidos direta ou indiretamente na construção e desenvolvimento do conceito de valência ao longo da segunda metade do século XIX e primeira metade do século XX, sendo Kekulé e Frankland os mais conhecidos e citados. O primeiro foi um químico orgânico alemão que se dedicou à elaboração da teoria dos tipos. Kekulé publicou inúmeros trabalhos nos quais apresentava aplicações e exemplos dos conceitos de tipo e de valência, principalmente em compostos orgânicos, para os quais estabeleceu uma teoria completa. Frankland foi um químico britânico que se dedicou à elaboração da teoria dos radicais, tendo sido muito influente na área de notação e na discussão sobre a relação da valência com os compostos orgânicos saturados e insaturados. As ideias de Kekulé e Frankland serão abordadas em maior profundidade nas seções seguintes, com destaque para a teoria dos tipos e a teoria dos radicais. Ambas possuíam o mesmo objetivo de organizar e explicar os compostos orgânicos, mas surgiram de forma praticamente independente e foram posteriormente unificadas, servindo como bases para a teoria de valência. ${ }^{25}$

Muitos outros cientistas contribuíram para o processo de elaboração do conceito de valência. A seguir são citados alguns, seguindo o levantamento feito por Russell. ${ }^{25}$ Odling foi um químico britânico que facilitou a propagação da ideia de valência por criar uma primeira forma de notação (aspas escritas junto com o símbolo do elemento químico). Williamson, químico britânico, foi um dos criadores do conceito de tipo químico, trabalhou na identificação de radicais poliatômicos e depois de tipos condensados, tendo sido um grande apoiador e divulgador da teoria atômica e de sua relação com o conceito de valência. ${ }^{33,37}$ Kolbe foi um químico alemão que trabalhou intensamente na parte experimental, obtendo muitos dados que foram interpretados como apoio às teorias de outros químicos, como Frankland, tendo também colaborado na elaboração da teoria do carbono tetravalente. Couper, químico britânico, por ter morrido muito jovem foi rapidamente esquecido, mas trabalhou intensamente na produção de dados e na construção de uma notação para a valência. Alexander Crum Brown (1838 - 1922) deu continuidade aos trabalhos de Couper e acabou ganhando os créditos por trabalhos de seu professor, como a notação da valência por meio de traços entre os símbolos dos elementos. ${ }^{25,30}$ 
Há ainda outros que não foram incluídos diretamente por Russell entre os que ele chamou de "fundadores da teoria de valência", mas que são citados pelo próprio Russell e outros autores no contexto da história desse conceito. Por exemplo, Mendeleev incorporou ideias sobre a valência em sua classificação periódica; Loschmidt criou a representação por círculos, depois aperfeiçoada por Kekulé; Werner foi um dos defensores e estudiosos da valência variável e da estrutura química em compostos inorgânicos; Butlerov realizou inúmeros trabalhos em termos da estrutura química dos compostos; Stanislao Canizzaro (1826 - 1910) estudou os metais e suas múltiplas valências, e trabalhou na determinação de pesos atômicos - entre outros. Observa-se, portanto, que o conceito de valência não pode ser atribuído a um único cientista, mas resultou de contribuições de muitos autores.

\section{CONCEPÇÕES DE VALÊNCIA - DIFERENTES NOMENCLATURAS E NOTAÇÕES}

A nomenclatura e a notação usadas para esse conceito se modificaram ao longo do tempo, assim como o próprio conceito. No período estudado, segunda metade do século XIX e primeira metade do século XX, é possível caracterizar três concepções distintas para a valência: inicialmente, como [1] propriedade numérica dos átomos; depois, como uma [2] interação entre os átomos; e, por último, como [3] sinônimo de ligação química. ${ }^{25}$

Em relação à concepção [1], Russell, ${ }^{25}$ assim como Kuznetsov, ${ }^{18}$ cita as diferentes classificações dadas aos elementos químicos usando o referido conceito como critério, ou seja, classificavam-se os elementos de acordo com seu número de valência. Entendia-se a valência como força de combinação, considerada intrínseca ao elemento e, portanto, independente das condições e dos outros átomos aos quais o elemento se une. Quando o termo usado era basicidade, os elementos eram classificados usando-se um prefixo designativo de um numeral, seguido pela palavra básico, ou seja, monobásico, dibásico, e assim por diante. Quando o termo empregado era atomicidade, a classificação se dava usando o prefixo de numeral seguido da palavra atômico, ou seja, monoatômico, diatômico, e assim por diante. Quando o termo escolhido passou a ser valência, ou um de seus correlatos (equivalência e quantivalência), houve duas nomenclaturas. Em uma delas, o prefixo de numeral era seguido do radical valente, ou seja, univalente, bivalente, etc., nomenclatura que foi apresentada e utilizada pela primeira vez por August von Hofmann (1818 - 1892) em 1865, e é usada até os nossos dias. A segunda nomenclatura foi proposta por William Odling (1829 - 1921) em 1864, utilizando os termos mônada, díade, tríade, e assim por diante, termos mais relacionados à ideia de ligação química entre os elementos. ${ }^{18,25}$

Em relação à notação, duas formas foram utilizadas: primeiramente as aspas no canto superior direito do símbolo do elemento, como, por exemplo, H' e O', apresentada por Odling em 1855. Essa notação foi posteriormente substituída por algarismos romanos na mesma posição, como, por exemplo, $\mathrm{H}^{\mathrm{I}}$ e $\mathrm{O}^{\mathrm{II}} .^{38}$

A concepção de valência [2], que se refere à interação entre os átomos, difere da concepção anterior, uma vez que não se trata mais de uma propriedade intrínseca do elemento, mas sim dependente do outro átomo ao qual se une. Essa concepção era a mais presente durante o século XIX, devido à dificuldade existente na época em se estudar os átomos de forma isolada, sendo mais fácil estudar seus compostos. Nesse contexto, foram utilizados inicialmente o termo afinidade, depois atomicidade e, por fim, valência. É preciso deixar claro que o termo atomicidade não tinha, no século XIX, o mesmo significado que tem na atualidade, ou seja, naquela época se referia à afinidade entre dois elementos, e não à quantidade de átomos em uma molécula, como consideramos hoje em dia.
Ainda nessa concepção, uma primeira notação com parênteses ou chaves entre os elementos ou grupos de elementos (tipos ou radicais, conforme as teorias que serão descritas nas seções posteriores) foi usada por Williamson, Adolph Kolbe (1818 - 1884), Charles Gerhardt (1816 - 1856), Frankland, Butlerov, entre outros, conforme exemplificado na Figura 1.$$
\left\{\begin{array}{l}
\mathrm{CH}_{3} \\
\mathrm{CH}_{3}
\end{array}\right.
$$

Figura 1. Representação por chaves (reproduzido da ref. 25, p. 95)

Essa notação foi criticada por Frankland, ${ }^{39}$ que apontou a existência de mais de uma notação para um mesmo composto, dependendo dos tipos ou radicais considerados. Johann Loschmidt (1821 - 1895) propôs uma forma de representação utilizando círculos, cujo contato representava uma ligação química, a intersecção uma ligação múltipla, e tamanhos ou cores distintas representavam átomos distintos (Figura 2).

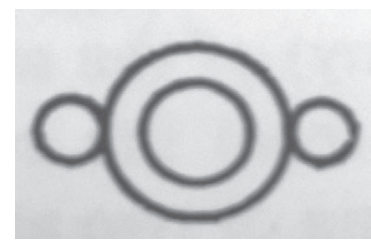

Figura 2. Molécula de água conforme a representação por círculos (reproduzida da ref. 25, p. 97)

Essa notação foi modificada por Kekulé, que relacionava o tamanho da representação para o átomo com sua valência, de forma proporcional, como pode ser exemplificado pela Figura 3 (observa-se que o tamanho da representação do átomo de carbono sugere suas quatro valências, sendo o hidrogênio monovalente). A representação dos átomos nas longas cadeias carbônicas fez com que esse tipo de notação ficasse conhecida como "fórmulas salsichas".

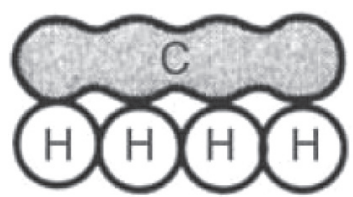

Figura 3. Representação de Kekulé: "fórmula salsicha” para o metano (reproduzido da ref. 4, p. 16)

Quanto à concepção [3] citada por Russell, ${ }^{25}$ tem-se a identificação entre valência e ligação química. Durante algum tempo, houve autores que consideraram esses termos como sinônimos, ainda que isso não fosse consenso na comunidade científica. Para evitar a confusão, alguns cientistas usaram atomicidade ou "valency" para indicar o poder de combinação dos átomos e "valence" ou ligação química para indicar a união entre dois átomos. ${ }^{25}$ Entretanto, essa diferenciação não chegou a alcançar grande difusão.

Nesse contexto em relação à notação, foi proposta a representação de linhas ligando os átomos, que inicialmente eram representados por círculos, e depois passaram a ser, por simplicidade, representados apenas pelos seus símbolos químicos, como pode ser visto nas Figuras 4 e 5.

Essa notação foi criada por Couper e Crum Brown, embora tenha sido conhecida somente pelo nome do último, e depois simplificada por Frankland, sendo usada até hoje. Tanto Crum Brown quanto Frankland ressaltaram que essa era apenas uma representação gráfica e não a realidade, sendo útil em muitos casos para explicar isomerismos e produtos de reação. ${ }^{24,25,38,40-45}$ 


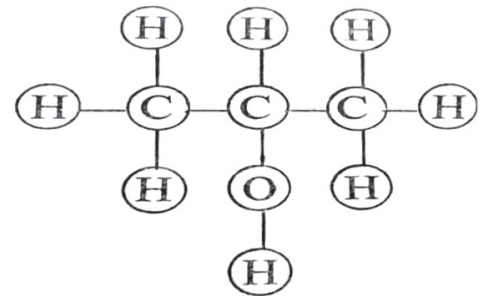

Figura 4. Representação por círculos e traços (reproduzido da ref. 25, p. 102)

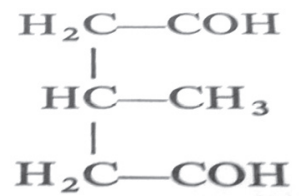

Figura 5. Representação simplificada (reproduzido da ref. 25, p. 107)

Antes do modelo de Crum Brown ser aceito e amplamente utilizado, as formas de notação acima citadas podiam coexistir para indicar ambos os aspectos (valência e ligação) dos radicais (podiam ser usados símbolos específicos para cada radical; por exemplo: "Me" para metila) e dos elementos, como se pode ver nas Figuras 6 e 7, retiradas de artigos de Frankland e B. F. Duppa. ${ }^{46,47}$ A notação com números e chaves foi explicada por Frankland em artigo de 1866, dedicado somente a esse tema. ${ }^{48}$

$$
\mathrm{Zn}^{\prime \prime}\left\{\begin{array}{l}
\mathrm{CH}_{3} \\
\mathrm{CH}_{3}
\end{array}\right.
$$

Figura 6. Representação por chaves e aspas (reproduzido da ref. 46, p. 30)

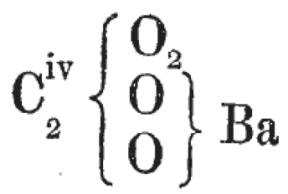

Figura 7. Representação por chaves e algarismos romanos (reproduzido da ref. 47, p. 18)

Em 1904, Richard Abegg (1868 - 1910) relacionou a valência com a distribuição eletrônica, conceituando valência (+) e contra-valência (-) como, respectivamente, o número de elétrons recebidos ou doados numa ligação. ${ }^{49}$ Alguns anos depois, Lewis propôs uma explicação eletrônica para a ligação química, e os traços passaram, então, a representar os elétrons compartilhados entre dois átomos, e não mais a valência dos elementos..$^{50,51}$

\section{A TEORIA DOS RADICAIS}

A teoria dos radicais surgiu no âmbito da química orgânica, uma área que, na metade do século XIX, ainda dava seus primeiros passos. Havia muitas questões em aberto, referentes à composição de certas substâncias, suas propriedades, suas reatividades, as causas da reatividade, etc., para as quais a teoria dos radicais - assim como a teoria dos tipos - buscava encontrar respostas. Nesse processo, seus adeptos foram descobrindo novas substâncias e as classificando e caracterizando. Essas teorias buscavam identificar o que haveria em comum em diferentes compostos, como um grupo de átomos unidos de determinada forma e que se conservaria ao se transformar um composto em outro. Esses grupos de átomos seriam como peças de um jogo de montar, sendo que uma das teorias chamava essas peças de "tipos", e a outra, de "radicais". Havia, porém, diferenças entre essas duas teorias, como a possibilidade de se isolar esses grupos de átomos (somente aceita pela teoria dos radicais), e o tamanho dessas "peças" que constituiriam as substâncias.

Porém, as dificuldades dos químicos em isolar experimentalmente os radicais - uma vez que uma de suas características, segundo Russell ${ }^{25}$ e Camel $^{52}$ e colaboradores, era serem grupos de átomos que poderiam estar isolados ou em união com outro grupo, isto é, outro radical - levou à maior aceitação da teoria dos tipos, os quais não precisavam ser isolados para assim serem caracterizados. Além disso, esta teoria previa a mudança das propriedades dos tipos ao serem unidos a outros, enquanto a teoria dos radicais previa a manutenção de suas propriedades mesmo após a união com outros radicais, levando à formação de um produto com propriedades intermediárias entre os dois radicais que lhe deram origem - o que nem sempre era observado experimentalmente..$^{53}$

Nas primeiras décadas do século XIX, o químico sueco Berzelius havia proposto seu conhecido dualismo, segundo o qual todo composto químico (orgânico ou inorgânico) possuiria dois radicais, um positivo e outro negativo, que se saturariam formando uma substância neutra. ${ }^{30,43,52,54}$ Essa ideia é considerada por Gay ${ }^{30}$, Russell ${ }^{25}$ e Palmer ${ }^{26}$ como uma primeira ideia de valência, que influenciou a criação e o desenvolvimento da teoria dos radicais, pois Berzelius já considerava grupos de átomos que iriam se unindo e formando os compostos, os quais teriam propriedades semelhantes aos radicais que lhes deram origem.

A partir disso, muitos químicos começaram a trabalhar na identificação e na caracterização dos radicais, entendidos na época como conjuntos de átomos que se comportariam como se fossem elementos químicos, ou seja, teriam propriedades e reatividades próprias. Entre esses químicos, podemos destacar Kolbe, que trabalhou na síntese de radicais por meio de reações eletroquímicas e métodos de análise orgânica. Kolbe criou a chamada doutrina dos radicais emparelhados (1848), baseada nos trabalhos de Berzelius, a qual descrevia uma série de radicais e suas diversas combinações. Kolbe também se dedicou a estudos que buscavam reduzir os radicais ao mínimo possível, separando os chamados radicais simples (constituídos por apenas um elemento) dos radicais compostos (com mais de um elemento). ${ }^{25,29,53,55-57}$

Outro exemplo muito relevante das investigações em torno dos radicais foi a síntese e caracterização do radical cacodilo (que hoje é reconhecido como sendo a substância de fórmula molecular $\mathrm{C}_{4} \mathrm{H}_{6} \mathrm{As}_{2}$ ) e de seus derivados. Dessas investigações participaram diversos químicos, dentre os quais se destacaram Robert Bunsen (1811 - 1899), com uma série de artigos publicados entre 1837 e 1847, e Berzelius, que propôs o nome cacodilo (do grego "kakos" - mau e "od" - odor) devido ao odor repulsivo do composto. Esse radical foi o primeiro a ser isolado, e se acreditava possuir as características esperadas para um radical (ser isolável e ser encontrado como uma parte fixa em reações de adição e substituição). Esse feito renovou o ânimo dos químicos da época em trabalhar com a teoria dos radicais e, posteriormente, com a teoria de valência. Sobre isso, escreveu Roscoe em homenagem póstuma a Bunsen:

A pesquisa do cacodilo é de nosso interesse, não só porque, como vimos, nos fornece o primeiro exemplo de um radical isolável, mas também porque auxiliou Frankland e Kekulé a ilustrar mais exatamente o termo "valência química" (Roscoe, 1900, apud Russell, p. 27). ${ }^{25}$

Essa investigação deu origem a diversos outros trabalhos de síntese, como os de Frankland que, em suas tentativas de isolar os hipotéticos radicais metila e etila, acabaram por levá-lo aos chamados compostos organometálicos. Bunsen a considerou como 
um dos passos mais importantes no desenvolvimento da química orgânica. ${ }^{20,25,58}$

Conforme já mencionado, a teoria dos radicais teve Frankland como um de seus principais nomes. Inicialmente, Frankland trabalhou junto com Kolbe, e depois de forma independente, na síntese e caracterização de radicais, dando a eles nomes e fórmulas, como no caso do ácido metacetônico e seus derivados (ou seja, compostos que também possuíam o grupo ácido ou o grupo metacetônico) e, também, do cianeto. Algumas dessas sínteses foram questionadas por outros químicos da época, principalmente pelos adeptos da teoria dos tipos. ${ }^{29,59-62}$ Com o amadurecimento de seu trabalho, Frankland passou a se dedicar mais especificamente à síntese e caracterização de compostos organometálicos, os quais considerava como sendo uma classe dentro dos radicais, ou mesmo como uma classe de compostos formados por mais de um radical. Frankland utilizou a mesma metodologia adotada anteriormente em seu trabalho com os vários radicais orgânicos, realizando os mesmos tipos de análises com todos os produtos obtidos, ou seja, realizando destilações, testes de solubilidade, métodos para determinar pontos de fusão e ebulição e para definir a composição (porcentagem em massa dos elementos). Os detalhes dessas metodologias podem ser encontrados nos trabalhos de Frankland listados nas referências bibliográficas ao final deste artigo. ${ }^{39,48,59-65}$

A partir de 1852, Frankland propôs o conceito de poder de combinação dos átomos, que seria representado por um número constante para cada elemento e que seria característico dos compostos formados por ele. Utilizando esse critério, Frankland sistematizou uma série de elementos e radicais com o mesmo poder de combinação e com o mesmo caráter eletroquímico, ou seja, eletropositivos e eletronegativos. Essas séries permitiam estabelecer relações entre diversos compostos e prever a existência de novos compostos, a partir da substituição de radicais respeitando o poder de combinação de cada um deles. Por analogia, era possível também prever algumas das propriedades e a reatividade desses novos compostos. ${ }^{23,41,48,63-65}$

Frankland também estabeleceu uma classe de reações químicas chamadas de reações de oxidação e redução, com base na alteração do poder de combinação dos metais. Nas diferentes transformações químicas, o poder de combinação dos metais poderia ser usado em sua totalidade (que seria o comportamento dos compostos saturados, ou seja, com todas as valências ativas) ou em um valor menor (compostos insaturados, isto é, com algumas valências ativas e outras latentes). Assim sendo, diferenças na variação do poder de combinação de um dado metal implicariam em diferenças nas propriedades de seus compostos, sendo, porém, todos estáveis nas condições dos experimentos. Essa concepção demonstra que Frankland aceitava a ideia de valência variável. ${ }^{39,48,66}$

Frankland também relacionou seus compostos organometálicos com os tipos inorgânicos já estabelecidos, e criou uma nomenclatura única, unindo as duas teorias (dos tipos e dos radicais), baseada no que hoje conhecemos como valência. De acordo com essa nomenclatura, os compostos eram divididos em grupos de acordo com um elemento presente e com a sua valência, como se pode observar na citação a seguir, na qual são mencionados os grupos ternário (valência 3) e o de cinco átomos (valência 5):

... em especial, os compostos de nitrogênio, fósforo, antimônio e arsênio exibem a tendência desses elementos em formar compostos contendo 3 ou 5 equivalentes de outros elementos, e nessas proporções suas afinidades são mais bem satisfeitas. Assim, no grupo ternário temos $\mathrm{NO}_{3}, \mathrm{NH}_{3}, \mathrm{NI}_{3}(\ldots)$ e no grupo de cinco átomos, $\mathrm{NO}_{5}, \mathrm{NH}_{4} \mathrm{O}, \mathrm{NH}_{4} \mathrm{I}$... Sem oferecer qualquer hipótese acerca da causa desse agrupamento simétrico dos átomos, resta suficientemente evidente... que tal tendência ou lei prevalece e que, independente do caráter dos átomos que se unem, o poder de combinação do elemento que atrai (se me permitem o termo) é sempre satisfeito pelo mesmo número desses átomos (p. 440, grifo nosso) ${ }^{63}$

Nessa passagem, em geral identificada com a proposição do conceito de valência por Frankland, o autor não utiliza esse termo, mas a expressão poder de combinação. $\mathrm{O}$ trecho citado aqui se encontra no contexto de uma discussão a respeito da possibilidade de unificar as teorias dos tipos e dos radicais. Para Frankland, essa unificação era desejada e, buscando isso, conduziu novas pesquisas nos anos seguintes, preparando novas substâncias, especialmente compostos organometálicos, visando aumentar a lista de compostos e demonstrar com mais exemplos as valências por ele defendidas. . $^{39,63}$

Entretanto, como observou Araújo Neto:

Os argumentos de Frankland se baseavam em um conjunto restrito de regularidades e ele se recusava a constituir uma teoria a respeito. Isso favoreceu a apresentação de diversos contra-exemplos, que decorriam da confusão que atormentava as fórmulas empíricas, em função da ausência de uma demarcação clara entre os átomos e os equivalentes químicos. Esses exemplos e o fato de que a capacidade de combinação de um elemento podia variar minaram a ampla aceitação das ideias de Frankland (p. 15). ${ }^{4}$

Esses contraexemplos e as refutações das teorias eram propostos até pelos próprios químicos adeptos da teoria dos radicais. Isso pode ser visto em artigo de Kolbe publicado em 1855, no qual questionou resultados experimentais e as hipóteses de Williamson a respeito das constituições dos ésteres, álcoois e ácidos orgânicos, que diferiam daquelas defendidas por Kolbe.$^{67} \mathrm{O}$ mesmo autor, em outros artigos, questionou a própria teoria dos radicais, mostrando algumas de suas deficiências e questões não respondidas. ${ }^{53,56}$ Por exemplo, em artigo de 1851, Kolbe discutiu a necessidade de rever a definição de radical como um grupo inalterável de átomos, concepção que levava a dificuldades em explicar o resultado de certas reações de substituição. Kolbe reconheceu que, de acordo com a teoria eletroquímica,

a natureza de um composto não pode ser considerada como independente da natureza química dos seus constituintes. Este consenso... foi provavelmente o principal motivo pelo qual a questão da imutabilidade dos radicais orgânicos não foi objeto de investigação na medida que ela merece.

Pode-se considerar como incontestável que a teoria dos radicais em seu estado presente não basta para fornecer explicações apropriadas para as inúmeras metamorfoses resultantes da chamada substituição e que, por uma adesão contínua à imutabilidade dos radicais, a base da teoria dos radicais torna-se continuamente enfraquecida (p. 370-371). ${ }^{56}$

A teoria dos radicais foi amplamente baseada no dualismo eletroquímico de Berzelius, do qual decorreu uma das principais questões então sem resposta: como explicar as reações de substituição nas quais um radical negativo, como o cloro, por exemplo, podia substituir um radical positivo, como o hidrogênio, por exemplo (como no caso da produção de ácido tricloroacético a partir de ácido acético). Esse problema levou os químicos a criarem outras teorias e modelos, como a teoria unitária ou a teoria do núcleo de Auguste Laurent (1807 -1853), segundo a qual todo composto possuía um núcleo fundamental no qual as substituições poderiam ocorrer, formando um núcleo derivado. Dessa forma, o foco passava a ser a molécula e não mais o átomo que estava sendo substituído. Superava-se, assim, a questão da troca de 
um átomo positivo por um negativo, que deixava de ser considerada como o aspecto mais importante, desde que a molécula mantivesse suas principais propriedades. Dessa maneira, a química passou de uma teoria dualista, baseada em átomos positivos e negativos, para uma teoria unitarista, baseada em grupamentos de átomos, ou seja, em moléculas como o foco central. ${ }^{23,30,37,52,57,68}$

\section{A TEORIA DOS TIPOS}

A teoria dos tipos é considerada a que mais influenciou a teoria de valência, e tem sido mais estudada que sua contemporânea teoria dos radicais. Os adeptos da teoria dos tipos tiveram, na época, maior prestígio que os defensores da teoria dos radicais, e até recentemente têm recebido maior atenção por parte dos historiadores da ciência. ${ }^{25,66,69}$ Essa teoria foi influenciada pelos estudos de botânica da época, pois buscava uma classificação para os elementos químicos em famílias e gêneros, e abandonava a ideia de Berzelius de compostos formados por atração eletroquímica. ${ }^{38}$

A teoria dos tipos foi elaborada principalmente pela comunidade de químicos orgânicos, e se tornou a maior influência para a teoria da química orgânica de Kekulé e, por consequência, para o conceito de valência. Segundo Araújo Neto e Santos,

A noção de valência está intimamente relacionada com os primeiros passos da Química Orgânica. Pode-se dizer que a valência orientou e foi orientada pelos "programas de pesquisa orgânicos", muito antes de ser reconduzida à Química Inorgânica (p. 10) ${ }^{69}$

A teoria dos tipos surgiu em 1839, com Jean-Baptiste Dumas (1800 - 1884), químico francês que realizou muitos estudos sobre as reações de substituição orgânica e que criou os conceitos de tipos mecânicos e tipos químicos. De acordo com Dumas, tipos mecânicos eram grupamentos de átomos que se uniam para formar substâncias, e seriam responsáveis por sua fórmula geral. Os tipos químicos, por sua vez, também eram grupamentos de átomos, e seriam responsáveis pelas propriedades químicas das substâncias que constituíam. Os tipos mecânicos e químicos poderiam ou não ser iguais entre si. Foi somente em 1853 que o químico francês Gerhardt sistematizou os tipos em três grupos: o tipo água, o tipo hidrogênio e o tipo amoníaco, e os caracterizou como resíduos de reação que não existiriam isolados (ao contrário dos radicais, que poderiam ser isolados) e se uniriam formando os produtos. Esses resíduos de reação eram determinados por meio experimental, principalmente por destilação e estudo da decomposição das substâncias. A decomposição separaria os resíduos ou tipos que formariam o composto em estudo, permitindo simplificar as fórmulas e compreender as relações entre os compostos, como escreveu Dumas em 1834:

A fim de simplificar as fórmulas que, em geral, são complexas demais para que a mente seja capaz de compreender as relações, devemos pressupor que existe alguma organização na molécula. Assim, supomos que a oxamida pode ser representada por dois componentes binários, o óxido de carbono e um nitreto de hidrogênio (Dumas, apud Fisher, p.110). ${ }^{68}$

Na citação acima, o exemplo utilizado por Dumas foi o da oxamida (cuja fórmula molecular é representada atualmente por $\mathrm{C}_{2} \mathrm{H}_{4} \mathrm{~N}_{2} \mathrm{O}_{2}$ ). Ao ser analisada em laboratório, a oxamida foi decomposta em óxido de carbono e em um nitreto de hidrogênio (Dumas poderia estar se referindo à amônia ou à hidrazina), que resultariam de seus resíduos e que, portanto, permitiriam determinar os tipos que a comporiam.
Essa teoria foi amplamente aceita no âmbito da química orgânica, e levou a inúmeros estudos de fórmulas químicas e estruturais para os compostos, utilizando os tipos já conhecidos. Com base nos tipos, foi criada uma das primeiras classificações dos compostos, separando-os em séries de acordo com sua combinação e suas propriedades. Essas séries caracterizavam o que hoje chamaríamos de funções orgânicas, mas na época poucos usavam essa expressão. ${ }^{18,25,30,37,38,43,52,57,68}$ Neste ponto, pode-se ressaltar uma diferença entre a teoria dos tipos e a teoria dos radicais: aquela se baseava não apenas na composição dos compostos, mas também em sua reatividade. Assim, a teoria caracterizava os tipos considerando os produtos formados nas reações, a composição das substâncias e a possível estrutura das mesmas. ${ }^{30}$

Williamson, que originalmente trabalhava com a ideia de radicais, adotou a concepção de tipos, pois considerou que seus radicais não eram isoláveis. Ele foi o primeiro a, em 1850, relacionar os tipos com um poder de combinação, baseando suas fórmulas em torno de elementos bivalentes ou dibásicos, principalmente o oxigênio, e classificando os tipos de acordo com a relação com esses elementos. Esse poder de combinação era considerado como uma força que causava as reações e produzia os compostos. ${ }^{25,30}$

Em 1857, Kekulé caracterizou os tipos como um conjunto de átomos ou radicais que se combinam de acordo com sua basicidade, e que podiam ser modificados ou ter seus átomos substituídos, formando outros tipos, conforme regras estabelecidas experimentalmente. ${ }^{24,30}$ Após essa classificação inicial, Kekulé e Couper continuaram suas investigações especificamente na química orgânica. Em 1858, Kekulé propôs a tetravalência do carbono, sustentada por inúmeros exemplos de compostos e de reações, e a partir da qual se desenvolveram teorias estruturais da química orgânica baseadas em cadeias carbônicas e na possibilidade de ligações múltiplas, de modo a sempre respeitar a tetravalência do carbono em todos os compostos. $^{24,25,30,52}$ Assim, Kekulé classificou os compostos por ele já conhecidos, utilizando como critérios as cadeias carbônicas e suas modificações, seja por substituição ou por formação de compostos cíclicos. ${ }^{36}$ Kekulé criou também uma das primeiras teorias estruturais baseadas nas cadeias carbônicas e nos átomos polivalentes, como o oxigênio e o nitrogênio (ou seja, átomos que, assim como o carbono, possuíam uma valência maior do que a unidade). $\mathrm{O}$ átomo de hidrogênio caracterizava a valência unitária, e poderia ou não fazer parte dessas cadeias. ${ }^{24}$ Pode-se ainda afirmar que Kekulé foi um dos primeiros a mostrar a relação entre valência e pesos equivalentes (valência = peso atômico / peso equivalente), e a utilizar essa relação para demonstrar que alguns valores de pesos atômicos então aceitos estavam incorretos, e deveriam ser corrigidos considerando os respectivos pesos equivalentes. ${ }^{66}$

Pode-se observar que Kekulé estudou a química orgânica e seus tipos fazendo uso da valência (com os diferentes nomes atribuídos a esse conceito na época). Outros químicos, como Couper, estudaram os compostos orgânicos nessa época e chegaram a algumas conclusões diferentes. Couper admitia a existência do que ele chamou de afinidade eletiva, propondo a possibilidade de a valência não ser constante para determinado tipo ou elemento.

Segundo Rocke, ${ }^{24}$ os químicos Butlerov, Couper e Kekulé estiveram entre os primeiros a criticar a teoria dos radicais e a teoria dos tipos:

Kekulé reiterou seu ponto de vista de que tanto os radicais quanto os tipos seriam meramente relativos e convencionais, assim como conceitos mutuamente complementares. (...) [Butlerov] afirmava, concordando com Couper, que o mundo químico deveria exaltar um único princípio, a "atomicidade" [i.e., a valência] (...) A confiante e abrangente utilização desse princípio revelaria as relações químicas dos átomos químicos, 
o arranjo das ligações químicas, e resultaria finalmente em uma compreensão completa da estrutura química (p. 32 e 36, grifos no original). ${ }^{24}$

Butlerov e Couper afirmavam que tanto a teoria dos tipos quanto a dos radicais seriam muito limitadas, pois apenas alguns compostos e elementos as seguiriam. Segundo esses autores, havia muitas exceções que as desacreditavam, como a questão da isomeria, e que se devia buscar um princípio geral para a química, que poderia ser a teoria de valência. ${ }^{4,24,25,30}$ Butlerov também alegou que os estudos deveriam focalizar a afinidade entre os elementos químicos - pois esta seria a responsável pela formação dos compostos, por suas propriedades e reatividade..$^{24,42}$ Finalmente, podem-se destacar as críticas de Frankland, adepto da teoria dos radicais, mas que também defendia sua unificação com a teoria dos tipos, afirmando que ambas possuíam pontos em comum e pontos positivos.

Além de recorrer ao termo "tipos" em diversos artigos, Frankland também afirmou que seus estudos dos compostos organometálicos o afastavam da teoria dos radicais e o aproximavam de outras teorias, como a dos tipos:

A formação e o exame dos corpos organometálicos prometem auxiliar uma fusão das duas teorias que por tanto tempo dividiram as opiniões dos químicos, e que foram precipitadamente consideradas irreconciliáveis. Pois, embora seja evidente que existem certos tipos de séries de compostos, também está claro que a natureza do corpo derivado do tipo original depende essencialmente do caráter eletroquímico de seus átomos individuais, e não apenas da posição relativa desses átomos. (...) É óbvio que o estabelecimento dessa visão da constituição dos compostos organometálicos os removerá da classe dos radicais orgânicos e irá relacioná-los de forma mais íntima com a amônia e as bases de Wurtz, Hofmann e Paul Thénard (p. 441-442). ${ }^{63}$

A amalgamação das duas teorias levou à formação da teoria de valência.

\section{ESTRUTURA QUÍMICA E VALÊNCIA}

A determinação da valência dos elementos e radicais, e seu uso na definição de fórmulas e estruturas químicas, foi feita de forma totalmente experimental, e baseada na tentativa e erro. Por meio de métodos experimentais eram determinados os elementos que compunham um composto e, em seguida, eram construídas todas as fórmulas possíveis usando a notação de Crum Brown (chamadas, originalmente, de diagramas de ligação). Tentava-se, então, determinar qual seria a fórmula mais provável, de acordo com as propriedades do composto e com os produtos formados em diferentes reações. ${ }^{26}$ Por esse método, tentava-se identificar tipos ou radicais cuja união pudesse resultar naquele novo composto, pois a discussão acerca da estrutura surgiu tanto no âmbito da teoria dos tipos quanto na dos radicais. ${ }^{1}$ Assim, diferentes estruturas podiam ser propostas para um mesmo composto. Segundo Araújo Neto, a valência era um conceito empírico que resultou da

percepção de uma regularidade na combinação dos elementos, mas principalmente na determinação de transpor essa regularidade para outros elementos, tornando-a uma propriedade geral dos corpos elementares e um conceito-chave para a criação da teoria estrutural. Valência e afinidade não são a mesma coisa. A valência é um produto da afinidade de um elemento (p. 21). ${ }^{4}$
Outro aspecto a ser considerado é que só foi possível haver a discussão sobre as fórmulas e as estruturas dos compostos após haver uma nomenclatura e um simbolismo aceitos por todos. ${ }^{43}$ Crum Brown, cuja representação foi amplamente aceita e usada, realizava estudos relacionando a estrutura com as propriedades dos compostos e, com isso, ressaltava a importância de sua notação. ${ }^{42}$

Kekulé e Kolbe consideravam as fórmulas estruturais como construtos totalmente empíricos, e que seria impossível comprovar sua realidade física. Por isso, ambos falavam em "fórmulas reacionais", que explicariam a reatividade dos compostos e permitiriam compará-los. Esse posicionamento é coerente com a posição mais conservadora e baseada em fatos e experimentos adotada por ambos, principalmente por Kolbe. ${ }^{24,25,29,30,34,57}$

Russell ${ }^{25}$ afirma que, embora haja uma disputa de prioridade sobre o termo "estrutura química", o primeiro a usá-lo teria sido Butlerov, em substituição ao termo "fórmula constitucional", utilizado por Emil Erlenmeyer (1825 - 1909). Camel e colaboradores ${ }^{52}$ concordam com essa informação, e indicam que a substituição de um termo pelo outro ocorreu no congresso de química realizado em 1861 em Speyer. Dessa forma, considerando os estudos realizados relacionando o arranjo espacial dos átomos e suas propriedades, o emprego da expressão "estrutura química", e a correlação feita entre a estrutura e a valência (ou atomicidade, como se dizia na época), Butlerov foi considerado por muitos como o fundador da teoria estrutural. ${ }^{52}$ Por outro lado, durante muito tempo a prioridade foi atribuída a Kekulé e Couper, que propuseram a tetravalência do carbono e a formação de cadeias carbônicas, contribuindo para a teoria estrutural. Pode-se afirmar, portanto, que a proposição e uso das estruturas químicas foi um processo gradual e feito em conjunto, começando com os trabalhos de Kekulé, passando pela sistematização e aprofundamento realizados por Butlerov (que aplicou a ideia de estrutura química aos compostos orgânicos até então conhecidos), e seguem sendo aperfeiçoados até os nossos dias - não cabendo falar em um único fundador. ${ }^{24,42}$

A partir dos estudos que relacionavam a estrutura química e a reatividade dos compostos, a química orgânica, baseada na concepção de cadeias carbônicas, começou a apresentar questões que levaram a um amadurecimento e aprofundamento das ideias de valência e de estrutura. Dentre essas questões estava o isomerismo, fenômeno no qual compostos com mesma composição elementar (logo, com mesma fórmula molecular) apresentam propriedades físico-químicas distintas. $\mathrm{O}$ isomerismo foi primeiro observado por Berzelius com o ácido tartárico e o ácido racêmico, e o conceito foi posteriormente aprofundado pelo estudo dos compostos orgânicos por Frankland e Dumas. Outra questão investigada na época foi a existência de compostos saturados e insaturados, os quais estavam relacionados, respectivamente, ao uso total ou parcial da valência de um átomo. Daí decorre a questão clássica a respeito de a valência ser constante ou variável, pois os dois modelos apresentavam exceções e não explicavam todos os compostos conhecidos. Em outros termos, colocava-se também a questão da igualdade da valência: se todas as valências seriam iguais, ou se algumas valências poderiam ser usadas apenas em parte. ${ }^{2,18,24,25,37,41,43,49}$ Somava-se a essas questões a dificuldade de se aceitar a tridimensionalidade das moléculas e visualizá-las, aspecto que só foi incorporado à teoria estrutural de Kekulé por Van’t Hoff e Le Bel no final do século XIX, quando ambos propuseram, de forma independente, as ideias de carbono tetraédrico e de isomeria espacial, ou seja, a existência do chamado átomo de carbono assimétrico..$^{70}$

Em relação à variação ou não da valência de determinado elemento, a principal questão era a validade da teoria da química orgânica, baseada na tetravalência do carbono. Para manter essa característica estável, Kekulé admitia a formação de ligações múltiplas entre os átomos de carbono e entre carbono e oxigênio, sendo que a presença dessas ligações explicaria diferentes propriedades e a reatividade dos 
compostos. Outros químicos da época, como Crum Brown, falavam sobre valências livres, reduzidas ou parciais, as quais explicariam uma afinidade residual nos átomos que possuíssem essa característica, aumentando a reatividade dos compostos nos quais eles estavam presentes. Por exemplo, um átomo que possui valência máxima igual a 4, mas está fazendo apenas 2 ligações, possuiria 2 valências livres, as quais seriam responsáveis por aumentar a reatividade do composto - pois esse átomo ainda teria possibilidade de formar mais ligações, ou seja, ainda possuiria a chamada afinidade residual. Henry Armstrong (1848-1937) chegou a relacionar essa afinidade residual à carga do elemento ou do composto, para explicar as propriedades de condutividade e os resultados dos processos de eletrólise. , $^{2,18,24-26,42} \mathrm{~A}$ relação entre o número de valência e a carga de um íon foi utilizada durante muito tempo ao longo do século XX.

\section{LIGAÇÃO QUÍMICA E VALÊNCIA}

Desde o início, o conceito de valência esteve relacionado com afinidade química e com a formação de "algo" entre os elementos que permitisse a eles ficarem juntos. Sendo assim, o termo valência durante muito tempo foi considerado como sinônimo de ligação química. Nas palavras de Araújo Neto e Santos, ${ }^{69}$ "Num mundo ainda sem elétrons, a valência é a causa da ligação química. Essa ligação, por sua vez, é formulada sem interesse em dar conta de suas causas" (p. 10-11). Segundo Russell, ${ }^{25}$ a falta de interesse em explicar a ligação e a estrutura química fez, em certo momento, diminuir a importância atribuída ao conceito de valência, devido a sua natureza empírica.

De acordo com Kuznetsov, ${ }^{18}$ houve uma evolução ao longo do tempo. Tem-se um estágio inicial, na metade do século XIX, no qual o número de valência era igual ao número de ligações químicas formadas por determinado elemento, como se vê no trabalho de Frankland. ${ }^{48}$ Chega-se, no início do século XX, à definição de valência em termos de pares de elétrons em torno dos átomos, os quais então definiriam o número de ligações químicas. Ou seja, o conceito de valência passou de algo mais empírico para algo mais teórico, de algo macroscópico (propriedade do elemento e sua reatividade) para algo submicroscópico (estrutura atômica e teoria da ligação de valência). ${ }^{18,48}$ Nesse caminho, outros termos foram utilizados, ou foram sendo diferenciados e mais bem definidos, como, por exemplo, número de coordenação e número de oxidação, antes considerados numericamente iguais ao número de valência, termo que muitas vezes prevalecia nas publicações e nos livros didáticos. ${ }^{11}$ Segundo Russell, ${ }^{66}$ Sutcliffe ${ }^{44}$ e Jensen, ${ }^{45}$ Frankland foi o responsável por difundir o termo "ligação química" em substituição ao termo "valência" - o qual, por possuir diversos significados, causava confusão. Porém, o próprio Frankland considerava que esta era uma questão apenas de nomenclatura. Em livro de 1866, ao comentar o significado das fórmulas gráficas utilizadas para representar os compostos, Frankland afirmou:

As linhas que conectam os diferentes átomos de um composto são apenas símbolos imperfeitos para os laços de união (bonds of union) entre eles; e sequer é necessário mencionar que não existem tais conexões materiais. As ligações (bonds) que de fato mantêm juntos os átomos de um composto, com toda a probabilidade, no que diz respeito à sua natureza, devem ser muito mais parecidas com aquelas que conectam os membros do nosso sistema solar (p. 25). ${ }^{71}$

Nesta citação, Frankland deixa claro que a ligação não existiria como um ente concreto, uma vez que para ele seria mais provável que os átomos estivessem ligados, como os planetas do sistema solar, por forças de atração à distância, em vez de fixos, como sugerido pela notação e pelo termo "ligação".

A gradativa elaboração do conceito de ligação química se deveu à tentativa de explicar a combinação dos elementos de forma mais detalhada, e que estivesse relacionada com a estrutura atômica. J. J. Thomson (1856 - 1940) criou um modelo atômico que envolvia partículas subatômicas de cargas negativas, posteriormente chamadas de elétrons. A partir desse modelo, Thomson criou uma teoria de ligação química que era caracterizada pela perda e ganho de elétrons. Dessa forma, um elemento se tornava positivo (o menos eletronegativo da dupla) e outro negativo (o mais eletronegativo da dupla), e por forças eletrostáticas se uniriam. Embora essa concepção estivesse de acordo com as teorias dualísticas, ela não explicava as ligações na maior parte dos compostos orgânicos, nem as substâncias formadas por apenas um elemento (como, por exemplo, $\mathrm{H}_{2}$ )..$^{72}$

Nos anos 1910, vários cientistas se empenharam em explicar a combinação dos elementos com base nos modelos atômicos de Thomson, de Niels Bohr (1885-1962) ou outros contemporâneos. Entre eles, o mais famoso e bem aceito foi o modelo de Lewis, o qual descreve a ligação química como transferência de elétrons entre dois elementos. Essa transferência poderia ser total - que seria o caso da ligação iônica, caracterizada pela formação de cargas nos átomos ou parcial. Os casos de transferência parcial poderiam ser de vários graus, desde os mais fracos, nos quais os elétrons se encontrariam igualmente compartilhados entre os dois átomos (por exemplo, no $\mathrm{H}_{2}$ ), até os mais fortes, nos quais o átomo mais eletronegativo atrairia mais os elétrons para si, porém ainda o compartilharia com o outro átomo.

Em artigo de 1916, Lewis publicou uma representação que ele havia criado alguns anos antes, registrada em memorando de 1902. Segundo ele, a ideia surgiu a partir da chamada "Lei de Abegg da valência e contravalência", de acordo com a qual "a diferença entre as valências máximas, positivas e negativas... de um elemento é, frequentemente, oito, e em nenhum caso é maior do que oito" (p. 767)..$^{50}$ Isso o levou a postular um modelo em que os elétrons de um átomo que participam de uma reação química estariam situados em sua região mais externa, e dispostos como nos vértices de um cubo (Figura 8). Assim, nas reações químicas, para um dado átomo o número de elétrons nessa camada poderia variar de zero a oito - o que permitiria explicar a citada Lei de Abegg.

Lewis utilizou também ilustrações para mostrar ligações como compartilhamento de pares de elétrons entre dois átomos, no contexto de uma possível explicação para ligações polares e apolares. ${ }^{50}$ A Figura 9 traz exemplos de representações para ligações simples e duplas entre átomos iguais.

No mesmo artigo, os compostos foram representados também por meio de estruturas que ficaram conhecidas como estruturas de Lewis, das quais alguns exemplos se encontram na Figura 10..$^{50,72-74}$

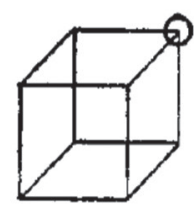

Li

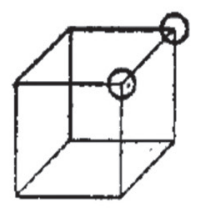

Be

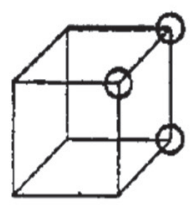

B
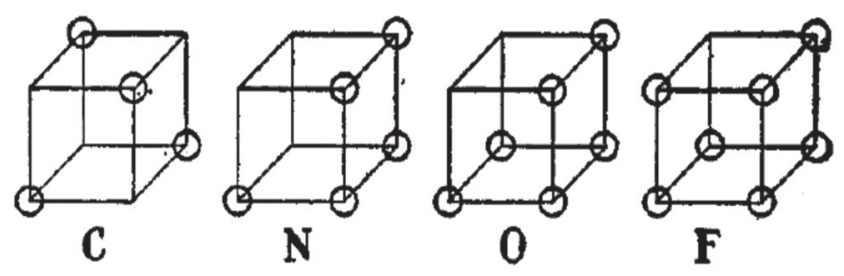

Figura 8. Modelos de Lewis para os “átomos cúbicos”, mostrando o número de elétrons na camada externa de alguns átomos (reproduzido da ref. 50, p. 767) 


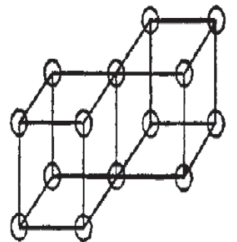

(i)

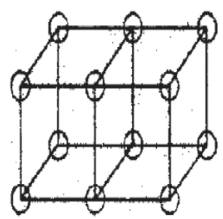

(ii)
Figura 9. Estruturas moleculares: (i) de um halogênio, $X_{2}$, exibindo um par eletrônico compartilhado entre os átomos; e (ii) do oxigênio, $\mathrm{O}_{2}$, exibindo dois pares eletrônicos compartilhados (reproduzido da ref. 50, p. 775 e 778)

$$
\begin{array}{cccc}
H & H & H & H \\
H: \ddot{C}: H & H: \ddot{N}: & : \ddot{O}: & : \ddot{F}: \\
\ddot{H} & \ddot{H} & \ddot{H} &
\end{array}
$$

Figura 10. Estruturas de Lewis (reproduzido da ref. 72, p. 345)

A teoria do par de elétrons compartilhados foi amplamente divulgada nos EUA pelo químico Irving Langmuir (1881 - 1957), que realizou várias conferências explicando essa nova teoria e a chamada regra do octeto, a qual indicava o número de elétrons da última camada dos átomos e que seriam utilizados para formar os pares eletrônicos. Essas conferências fizeram com que muitos creditassem a teoria a Langmuir e não a Lewis, o que gerou um desconforto entre os dois. Lewis publicou um livro e artigos nos quais deixava claro que era dele a prioridade sobre a criação do modelo de ligação por pares de elétrons, como se pode observar na seguinte citação:

A teoria tem sido designada em alguns lugares como teoria de Lewis-Langmuir, o que implicaria em algum tipo de colaboração. De fato, o trabalho do Dr. Langmuir foi totalmente independente: e os acréscimos que ele fez ao que foi afirmado ou estava implícito no meu artigo devem ser creditados somente a ele (Lewis, 1923, apud Jensen, p. 199). ${ }^{75}$
Esse modelo de ligação química, o qual era totalmente empírico, enfrentou resistências, em particular no que se refere aos "átomos cúbicos", nos quais os elétrons se encontravam em arranjos estáticos.

O conceito de ligação química continuou a ser elaborado nos anos seguintes, com os novos modelos atômicos de Ernest Rutherford (1871-1937), de Bohr e a teoria quântica, que levaram à separação final entre os conceitos de valência e de ligação química. As teorias da ligação de valência e dos orbitais moleculares correlacionam ambos os conceitos, mas os caracterizam como construtos distintos. De maneira resumida, se poderia dizer que a valência de um elemento seria a quantidade de elétrons em cada um de seus átomos que estariam disponíveis para serem compartilhados e formarem ligações com átomos de outros elementos químicos; e que a ligação química seria o resultado do compartilhamento de elétrons entre os átomos de dois elementos químicos, ou a combinação de seus orbitais atômicos. Dessa forma, pode-se entender que o conceito de valência volta a ser uma propriedade dos elementos químicos, a qual pode estar envolvida na formação da ligação química, mas não é a ligação química. ${ }^{3,4,28,44,49,51}$

\section{PERIODICIDADE QUÍMICA E VALÊNCIA}

Muitos livros didáticos mencionam a valência como uma propriedade periódica identificada por Mendeleev. Essa ideia é apontada por Palmer ${ }^{26}$ como verdade para as séries curtas da tabela periódica, mas não para as séries longas, que incluem os chamados metais de transição e os lantanoides e actinoides - estes, entretanto, não estavam presentes na tabela original de Mendeleev.

Williamson classificou os elementos de acordo com suas valências, e Frankland aperfeiçoou essa classificação usando o maior número de valência conhecido para cada elemento, incluindo dessa forma os elementos com valência variável. Em sua tabela periódica, Mendeleev havia indicado, para cada grupo da tabela, uma fórmula geral para os compostos que eles formavam com o oxigênio ou com o hidrogênio, elementos mais comuns e com maior número de compostos conhecidos na época. Essa fórmula geral aparecia no topo das colunas, ${ }^{25,30,52}$ como se observa na Figura 11, que reproduz uma tabela periódica de 1871.

\begin{tabular}{|c|c|c|c|c|c|c|c|c|c|}
\hline Série & $\begin{array}{c}\text { Gupo I } \\
- \\
\mathrm{R}^{2} \mathrm{O}\end{array}$ & $\begin{array}{c}\text { Grupo II } \\
- \\
\text { RO }\end{array}$ & $\begin{array}{c}\text { Grupo III } \\
- \\
\mathrm{R}^{2} \mathrm{O}^{3}\end{array}$ & $\begin{array}{c}\text { Grupo IV } \\
\mathrm{RH}^{+} \\
\mathrm{RO}^{2}\end{array}$ & $\begin{array}{c}\text { Grupo V } \\
\mathrm{RH}^{3} \\
\mathrm{R}^{2} \mathrm{O}^{5}\end{array}$ & $\begin{array}{c}\text { Grupo VI } \\
\mathrm{RH}^{2} \\
\mathrm{RO}^{3}\end{array}$ & $\begin{array}{c}\text { Grupo VII } \\
\text { RH } \\
\mathrm{R}^{2} \mathrm{O}^{\top}\end{array}$ & \multicolumn{2}{|c|}{$\begin{array}{c}\text { Grupo VIII } \\
- \\
\mathrm{RO}^{4}\end{array}$} \\
\hline $\begin{array}{l}1 \\
2\end{array}$ & $\begin{array}{l}\mathrm{H}=1 \\
\mathrm{Li}=7\end{array}$ & $\mathrm{Be}=9,4$ & $B=11$ & $\mathrm{C}=12$ & $\mathrm{~N}=14$ & $0=16$ & $\mathrm{~F}=19$ & & \\
\hline 3 & $\mathrm{Na}=23$ & $\mathrm{Mg}=24$ & $\mathrm{Al}=27,3$ & $\mathrm{Si}=28$ & $\mathrm{P}=31$ & $S=32$ & $\mathrm{Cl}=35,5$ & & \\
\hline 4 & $\mathrm{~K}=39$ & $\mathrm{Ca}=40$ & $-=44$ & $\mathrm{Ti}=48$ & $\mathrm{~V}=51$ & $\mathrm{Sr}=52$ & $\mathrm{Mn}=55$ & $\begin{aligned} \mathrm{Fe} & =56 \\
\mathrm{Ni} & =59\end{aligned}$ & $\begin{array}{c}\mathrm{Co}=59 \\
\mathrm{Cu}=63\end{array}$ \\
\hline 5 & $(\mathrm{Cu}=63)$ & $\mathrm{Zn}=65$ & $-=68$ & $=72$ & $A S=75$ & $\mathrm{Se}=78$ & $\mathrm{Br}=80$ & & \\
\hline 6 & $\mathrm{Rb}=85$ & $\mathrm{Si}=87$ & $2 Y_{t}=88$ & $\mathrm{Z}_{\mathrm{I}}=90$ & $\mathrm{Nb}=94$ & $\mathrm{Mo}=96$ & $=100$ & $\begin{array}{l}\mathrm{Ru}=104 \\
\mathrm{~Pb}=106\end{array}$ & $\begin{array}{r}\mathrm{Rh}=104 \\
\mathrm{Ag}=108\end{array}$ \\
\hline 7 & $(\mathrm{Ag}=108)$ & $\mathrm{Cd}=11.2$ & $\operatorname{In}=113$ & $S n=118$ & $\mathrm{Sb}=122$ & $\mathrm{Te}=125$ & $J=127$ & - & - \\
\hline 8 & $C s=133$ & $\mathrm{Ba}=137$ & $2 \mathrm{Di}=138$ & $\gamma \mathrm{Ce}=140$ & - & - & - & & \\
\hline 9 & $(-)$ & - & - & - & - & - & - & & \\
\hline 10 & - & - & $9 \mathrm{Er}=178$ & $? \mathrm{La}=180$ & $\mathrm{Ta}=182$ & $W=184$ & - & $\begin{array}{c}\mathrm{Os}=195 \\
\mathrm{Pt}=198\end{array}$ & $\begin{array}{c}\mathrm{II}_{\mathrm{r}}=197 \\
\mathrm{Au}=199\end{array}$ \\
\hline 11 & $(\mathrm{Au}=199)$ & $\mathrm{Hg}=200$ & $T l=204$ & $\mathrm{~Pb}=207$ & $\mathrm{Bi}=208$ & - & - & & \\
\hline 12 & - & - & - & $T h=231$ & - & $\mathrm{U}=240$ & - & - & - \\
\hline
\end{tabular}

Figura 11. Tabela Periódica indicando hidretos e óxidos mais comuns para cada grupo (reproduzido da ref. 76, p. 111) 
Na segunda metade do século XIX, as fórmulas eram obtidas por meio das valências, ou a valência era obtida pela composição que dava origem à fórmula. Entretanto, a existência de valências múltiplas para um mesmo elemento poderia levar a seu questionamento como propriedade periódica, pois as valências múltiplas não variavam de forma regular. ${ }^{25}$

O estabelecimento de uma correlação entre o sistema periódico e a valência, e a credibilidade dada àquele sistema após o advento das teorias eletrônicas, renovaram a utilidade do conceito de valência, embora houvesse dificuldades com alguns elementos do meio da tabela periódica (metais de transição). As principais características atribuídas ao conceito de valência no contexto do sistema periódico foram: a igualdade entre o número máximo de valência de um elemento e o número do grupo no qual esse elemento se encontra; a valência como uma propriedade que define os compostos formados, sua estabilidade e algumas de suas propriedades; e a relação da valência com a eletroquímica, em termos de carga do cátion ou ânion do elemento, fornecendo assim um caráter positivo ou negativo para a valência e relacionando-a de uma forma mais direta com a teoria eletrônica, ou seja, com a quantidade de elétrons nos átomos. Nesse mesmo contexto, a criação da teoria do octeto consolidou a aceitação do número máximo de valência como sendo oito, o que já era aceito e defendido por alguns químicos da época com base empírica, ou seja, pela observação dos compostos até então conhecidos, o que depois foi explicado em termos de quantidade de elétrons pela teoria eletrônica. Cabe, porém, ressaltar que essa teoria é válida apenas para parte da tabela periódica e para alguns compostos e, por isso, atualmente existem outras teorias na química de coordenação, mais sofisticadas, que abrangem valências maiores que oito para determinados elementos em seus compostos. . $^{3,18,49}$

\section{CONSIDERAÇÕES FINAIS}

Este estudo de caso histórico permite observar alguns aspectos do complexo processo de construção e transformação do conceito de valência. $\mathrm{O}$ trabalho de Frankland em busca da preparação dos radicais metila e etila o levou, inesperadamente, à síntese e posterior caracterização dos compostos organometálicos. É curioso considerar que, assim como os compostos organometálicos representam um ponto de intersecção entre a química orgânica e a inorgânica, foi no contexto de sua síntese que Frankland observou e explicitou a quantificação do "poder de combinação" dos elementos - dando assim um importante passo em direção a outra combinação: a da teoria dos tipos com a teoria dos radicais. Uma das questões fundamentais da química orgânica, então em desenvolvimento, se referia à estrutura das substâncias: para aprofundar o entendimento sobre a combinação entre os elementos, os químicos buscaram estabelecer a distribuição espacial das valências dos elementos. Além disso, buscava-se compreender a natureza da combinação entre os elementos, ou seja, quais forças estavam envolvidas, ou o que fazia com que determinados elementos se unissem e outros não. No que tange a essa questão, o desenvolvimento de teorias sobre a ligação química buscava definir o que seria a valência, ou seja, fazer com que esse conceito deixasse de ser puramente empírico e ganhasse correspondência com alguma entidade físico-química. Os resultados observados nesta investigação sugerem, em vez de uma ruptura paradigmática no sentido kuhniano, um processo gradual, no qual as novas teorias para a estrutura eletrônica dos átomos foram sendo "enxertadas" no modelo clássico de valência, gerando "híbridos férteis", como os tipos de ligação química (chamadas, por certo período, de eletrovalência e covalência). Ao longo desse processo, foram propostas explicações teóricas para as propriedades periódicas dos elementos observadas empiricamente.
Implicações para o ensino de química poderão resultar deste estudo de caso - o qual já serviu como referência para a análise da apresentação do conceito de valência em livros didáticos de química geral destinados ao ensino superior publicados nos EUA nas primeiras décadas do século XX. ${ }^{77}$ Além disso, o estudo de caso pode orientar a elaboração de planos de aula para o ensino médio ou superior, nos quais os professores discutam alguns aspectos da construção do conceito (como a relação entre as fórmulas químicas e a valência) ou da própria natureza da ciência (como o uso e o abandono de modelos, exemplificado pelos átomos cúbicos de Lewis; ou o caráter dinâmico da ciência, exemplificado pela multiplicidade de contribuições de diferentes cientistas, e a convergência de duas teorias concorrentes que levou à teoria da valência). São algumas possibilidades que se oferecem aos professores de química para inserir o viés histórico em suas abordagens para o conceito de valência.

\section{AGRADECIMENTOS}

Os autores agradecem à Fundação de Amparo à Pesquisa do Estado de São Paulo (FAPESP) pela concessão de bolsas de mestrado (2016/09213-5) e de pesquisa no exterior (2014/24213-6), ao Conselho Nacional de Desenvolvimento Científico e Tecnológico (CNPq) pelo auxílio à pesquisa (426519/2016) e pela concessão de bolsa de produtividade em pesquisa (307652/2017-3).

\section{REFERÊNCIAS}

1. Rocke, A. J.; Br. J. Hist. Sci. 1981, 14, 27.

2. Kauffman, G. B. J.; Chem. Educ. 1972, 49, 813.

3. Zavaleta, D. J.; Chem. Educ. 1988, 65, 677.

4. Araújo Neto, W. N.; Cad. Temáticos Quím. Nova Esc. 2007, 7, 13.

5. Jones, E. V.; J. Chem. Educ. 1945, 22, 74.

6. Flood, E. A.; J. Chem. Educ. 1935, 12, 132.

7. Frank, J. O.; J. Chem. Educ. 1929, 6, 718.

8. Zimmermann, J. A. E.; J. Chem. Educ. 1925, 2, 383.

9. Wakeham, G.; J. Chem. Educ. 1946, 23, 43.

10. Burt, C. P.; J. Chem. Educ. 1930, 7, 2124.

11. Garritz, A.; Rincon, C.; Educ. Quím. 1997, 3, 130.

12. Toma, H. E.; Quim. Nova Esc. 1997, 6, 8.

13. Bezerra, A. S.; Silva, R. R.; Educ. Quím. 2001, 12, 179.

14. Kragh, H.; Introdução à historiografia da ciência. Porto Editora: Porto, 2001.

15. Debus, A. G.; Revista da Sociedade Brasileira de História da Ciência 1991, 5, 3 .

16. Escrevendo a história da ciência: tendências, propostas e discussões historiográficas; Alfonso-Goldfarb, A. M., Beltran, M. H. R., orgs.; EDUC/Livraria da Física/Fapesp: São Paulo, 2004.

17. Canguilhem, G.; Revista de Metodologia de Ciencias Sociales 2009, 18 , 195.

18. Theory of valency in progress; Kuznetsov, V. I., org.; Moscou: Mir Publishers, 1980.

19. Russell, C. A.; Instruments and Experimentation in the History of Chemistry. The MIT Press: Cambridge, 2000.

20. Seyferth, D.; Organometallics 2001, 20, 2940.

21. Frankland, E.; Quarterly Journal of the Chemical Society of London 1854, 6, 197.

22. Frankland, E.; Philos. Trans. R. Soc. London 1855, 145, 259.

23. Frankland, E.; Philos. Trans. R. Soc. London 1856, 146, 59.

24. Rocke, A. J.; Ambix 1983, 30, 1.

25. Russell, C. A.; History of valency. Chicago: University of Chicago Press: Chicago, 1971.

26. Palmer, W. G.; Valency: classical and modern. The University Press: Cambridge, 1944. 
27. Shaik, S.; Hilbert, P. C.; Rev. Comp. Chem. 2004, 20, 1.

28. Ballhausen, C. J.; J. Chem. Educ. 1979, 56, 215.

29. Rocke, A. J.; Osiris 1993, 8, 52.

30. Gay, H.; Studies in History and Philosophy of Science 1979, 7, 1.

31. Pippard, B.; Notes and Records of the Royal Society of London 2002, $56,63$.

32. Brock, W. H.; Ambix 2013, 60, 203.

33. Brock, W. H.; Knight, D. M.; Isis 1965, 56, 5.

34. Chalmers, A. F.; Found. Chem. 2008, 10, 157.

35. Russell, C. A.; Ambix 1987, 34, 169.

36. Fisher, N. W.; Ambix 1974, 21, 29.

37. Bensaude-Vincent, B.; Stengers, I.; História da Química. Instituto Piaget: Lisboa, 1992.

38. Camel, T. O.; Tese de doutorado, Universidade Federal do Rio de Janeiro, Brasil, 2010.

39. Frankland, E.; Quarterly Journal of the Chemical Society of London 1861, 13, 177.

40. Crum-Brown, A.; On the Theory of Chemical Combination: a Thesis. Edinburgh, 1861.

41. Frankland, E.; Duppa, B. F.; Philos. Trans. R. Soc. London 1866, 156, 309.

42. Larder, D. F.; Ambix 1971, 18, 26.

43. Kolb, D.; J. Chem. Educ. 1978, 55, 44.

44. Sutcliffe, B. T.; Int. J. Quantum Chem. 1996, 58, 645.

45. Jensen, W. B.; J. Chem. Educ. 2009, 86, 791.

46. Frankland, E.; Duppa,B. F.; J. Chem. Soc. 1864, 17, 29

47. Frankland, E.; Duppa, B. F.; Proc. R. Soc. London 1865, 14, 17.

48. Frankland, E.; J. Chem. Soc. 1866, 5, 372.

49. Badillo, R. G.; Miranda, R. P.; Beltrán, M. V. U.; Fernandez, L. C.; Rodríguez, R. Y. A.; Ciência \& Educação 2004, 10, 571.

50. Lewis, G. N.; J. Am. Chem. Soc. 1916, 38, 762.

51. Laszlo, P.; Chem. Educ.: Res. Pract. Eur. 2002, 3, 113.

52. Camel, T. O.; Koehler, C. B. G.; Filgueiras, C. A. L.; Quim. Nova 2009, 32, 543.

53. Kolbe, A. W. H.; Quarterly Journal of the Chemical Society of London 1852, 4,41 .
54. Pulido, M. D.; Dissertação de Mestrado, Universidade de São Paulo, Brasil, 2016.

55. Kolbe, A. W. H.; Quartely Journal of the Chemical Society of London 1850, 2, 157.

56. Kolbe, A. W. H.; Quarterly Journal of the Chemical Society of London 1851, 3, 369.

57. Rocke, A. J.; Ambix 1987, 34, 156.

58. Bunsen, R. W. E.; Memoirs of the Chemical Society 1841, 1, 63.

59. Frankland, E.; Kolbe, A. W. H.; Memoirs and Proceedings of the Chemical Society 1845, 2, 386.

60. Frankland, E.; Kolbe, A. W. H.; Quarterly Journal of the Chemical Society of London 1849, 1, 60.

61. Frankland, E.; Quarterly Journal of the Chemical Society of London 1851, 3, 322 .

62. Frankland, E.; Philos. Trans. R. Soc. London 1862, 152, 167.

63. Frankland, E.; Philos. Trans. R. Soc. London 1852, 142, 417.

64. Frankland, E.; Philos. Trans. R. Soc. London 1859, 149, 401.

65. Wanklyn, J. A.; Frankland, E.; Proc. R. Soc. London 1858, 9, 341.

66. Russell, C. A.; Edward Frankland - Chemistry, Controversy and Conspiracy in Victorian England. Cambridge University Press: Cambridge, 1996

67. Kolbe, A. W. H.; Quarterly Journal of the Chemical Society of London $1855,7,111$.

68. Fisher, N. W.; Ambix 1973, 20, 106.

69. Araújo Neto, W. N.; Santos, J. M. T.; Atas do III Encontro Nacional de Pesquisa em Educação em Ciência, Atibaia, Brasil, 2001.

70. Ramberg, P. J.; Somsen, G. J.; Ann. Sci. 2001, 58, 51.

71. Frankland, E.; Lecture notes for chemical students embracing mineral and organic chemistry. John Van Voorst: Londres, 1866.

72. Kohler Jr., R. E.; Hist. Stud. Phys. Sci. 1971, 3, 343.

73. Stranges, A. N.; J. Chem. Educ. 1984, 61, 185.

74. Pauling, L.; J. Chem. Educ. 1984, 61, 201.

75. Jensen, W. B.; J. Chem. Educ. 1984, 61, 191.

76. Rocha-Filho, R. C.; Chagas, A. P.; Quim. Nova 1997, 20, 103.

77. Nogueira, H. S. A.; Porto, P. A.; Quim. Nova 2018, DOI: 10.21577/01004042.20170310 